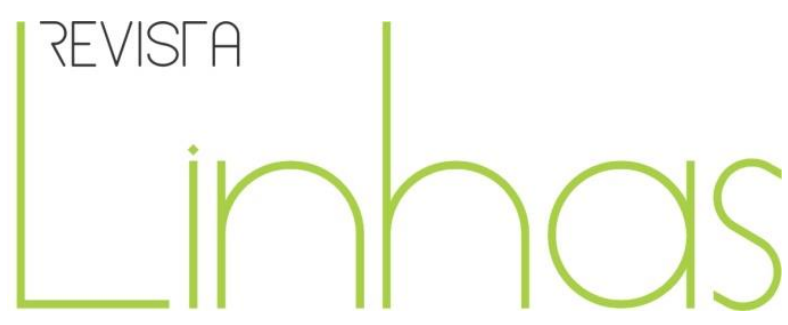

\title{
Organização do trabalho pedagógico em escolas do campo: limites e possibilidades
}

\section{Resumo}

À luz de um referencial teórico histórico-dialético, este texto discute questões relacionadas à organização do trabalho pedagógico nas escolas do campo, considerando os principais desafios da atual conjuntura do meio rural brasileiro. Como questão de fundo, traz à tona o debate da especificidade, ou não, da escola do campo. Entendemos que a expropriação do trabalho do homem do campo, bem como a precarização da condição de vida e a miséria ocasionam grande impacto social no meio rural, e contribuem para o esvaziamento do campo. E neste contexto de mudanças na configuração do rural e nas condições objetivas de vida, mudou também o homem, o trabalhador do campo. Neste sentido, o sujeito do campo não pode ser pensado como alguém isolado, excluído completamente de quaisquer resquícios de desenvolvimento. Diante do contexto da reestruturação produtiva e das novas formas de organização do trabalho rural, houve uma ampliação e uma diversificação de atividades, divididas entre agrícolas e não agrícolas, de maneira que os trabalhadores foram obrigados a residir onde quer que sua materialidade minimamente esteja garantida. E no sentido de apreender as formas de organização da vida no campo, e, sobretudo da escola do campo buscamos pinçar alguns elementos para pensarmos a educação na atualidade.

Palavras-chave: Trabalho pedagógico; Escolas rurais; Educação rural.
Adriana do Carmo de Jesus

Doutoranda em Educação pela

Universidade Federal de São

Carlos - UFSCar - Brasil

adrianapedago@gmail.com

Maria Cristina dos Santos Bezerra

Professora no Departamento de Educação da Universidade Federal de São Carlos - UFSCar. Doutora em Educação pela Universidade estadual de Campinas - UNICAMP - Brasil cbezerra@ufscar.br

\section{Para citar este artigo:}

BEZERRA, Maria Cristina dos Santos; JESUS, Adriana do Carmo de. Organização do trabalho pedagógico em escolas do campo: limites e possibilidades. Revista Linhas. Florianópolis, v. 17, n. 33, p. 238-260, jan./abr. 2016. 


\title{
Labour in schools rural educational: limits and possibilities
}

\begin{abstract}
The light of a theoretical historical-dialectical framework this paper discusses issues related to the organization of education work in schools in the rural, considering the main challenges of the current situation of the Brazilian countryside. As a matter of background brings up the specificity, or not, the rural school. We understand that the expropriation of labor of the peasant as well as deterioration of living conditions and poverty cause great social impact in rural areas, and contribute to the emptying of the countryside. And in this context of change in the rural and the objective conditions of configuration, also changed the man, the rural worker. In this sense, the subject of the rural can not be thought of as someone isolated, completely deleted any traces of development. Given the context of productive restructuring and new forms of organization of rural labor, there was an expansion and diversification of activities, so that the works were forced to live wherever their materiality are minimally guaranteed. And in order to grasp the forms of organization of rural life, and especially rural school pinch seek some elements to think of education today.
\end{abstract}

Keywords: Pedagogical work; Rural schools; Rural education. 
Este texto é o resultado parcial de uma pesquisa realizada ao longo do curso de mestrado no Programa de Pós-Graduação em Educação da Universidade Federal de São Carlos. Traz em seu bojo a discussão acerca da concepção de educação do campo atualmente em voga, e da organização do trabalho pedagógico desenvolvido em escolas do campo localizadas no interior do estado de São Paulo.

Tratar em um artigo a temática da organização do trabalho pedagógico e, sobretudo, a organização do trabalho pedagógico em escolas do campo é assumir a responsabilidade e os riscos de não contemplar, com a profundidade que este tema requer os desdobramentos inerentes ao cotidiano escolar. Temos como objetivo neste texto ampliar o debate acerca da temática e introduzir alguns pontos para reflexão considerando as relações pedagógicas que se configuram entre aluno-professorconhecimento.

Sabe-se que as relações que se estabelecem no interior da escola são marcadas por relações sociais mais amplas; a educação não pode ser pensada de forma descolada de um contexto social mais amplo. A escola não é um objeto posicionado fora da sociedade de classes, sofre os reflexos impactantes das transformações sociais e à medida que as condições históricas vão se alterando, a escola também sofre alterações, sendo que, na sociedade capitalista, a escola assume características ímpares. Assim, verifica-se que as relações de exploração, a negação dos direitos sociais e a expropriação do trabalhador, características próprias da indústria capitalista, também estão presentes na realidade no campo, e consequentemente, há a forte tendência em transformar o homem e a natureza em mercadorias. Tendência na qual o lucro e a acumulação de capital têm mais importância que a vida humana, que o trabalhador e, nesta lógica capitalista, quanto mais o trabalhador produz, tanto menos ele possui e mais é submetido à miséria. Para Marx (1964)

O trabalhador torna-se mais pobre quanto mais riqueza produz, quanto mais a sua produção aumenta em poder e extensão. $O$ trabalhador tornase uma mercadoria tanto mais barata, quanto maior número de bens que produz. Com a valorização do mundo das coisas aumenta em proporção 
direta a desvalorização do mundo dos homens. O trabalho não produz apenas mercadorias; produz-se também a si mesmo e ao trabalhador como mercadoria, e justamente na mesma proporção com que produz bens. (MARX, 1964, p. 159)

A expropriação do trabalho do homem do campo, bem como a precarização da condição de vida e a miséria ocasionaram, e ainda têm ocasionado grande impacto social no meio rural, e contribuem para o esvaziamento do campo. E, neste contexto de mudanças na configuração do rural e nas condições objetivas de vida, mudou também o homem, o trabalhador do campo, que não pode ser pensado, ainda hoje, como alguém atrasado, isolado, excluído completamente de quaisquer resquícios de desenvolvimento. Diante do contexto da reestruturação produtiva, que atingiu também o campo, e das novas formas de organização do trabalho rural, houve uma ampliação e uma diversificação das atividades produtivas no campo, de maneira que os trabalhadores foram obrigados a residir onde quer que sua materialidade minimamente esteja garantida.

Discutiremos questões relacionadas à organização do trabalho pedagógico nas escolas do campo, considerando os principais desafios da atual conjuntura do meio rural brasileiro. Como questão de fundo, traremos o debate da especificidade, ou não, da escola do campo.

E no sentido de apreender as formas de organização da vida no campo, e, sobretudo da escola do campo, buscamos pinçar alguns elementos para pensarmos a educação na atualidade.

\section{A educação escolar e a organização do trabalho pedagógico}

O processo de desenvolvimento histórico da escolarização da classe trabalhadora no meio rural brasileiro de fato é lento. O Brasil chega ao século XXI com déficits na escolarização dos trabalhadores do campo. Dados do IBGE (2012) $)^{1}$ sinalizam que há grandes desigualdades entre a escolarização da classe trabalhadora e da classe média no

\footnotetext{
${ }^{1}$ Disponível em http://www.ibge.gov.br/home/estatistica/populacao/estimativa2012/
} 
país, e quando comparamos os processos de escolarização oferecidos à classe trabalhadora urbana e a classe trabalhadora do meio rural, percebe-se que ambos são de baixa qualidade, mas, sobretudo percebe-se que as escolas rurais frequentemente são mais penalizadas com a escassez ou falta de recursos, fechamento de unidades por conta do processo de nucleação dentre outros fatores que afetam essas escolas.

Portanto, o foco na escola do campo não implica na opção de se estabelecer uma dicotomia entre escola rural - escola urbana, mas sim em uma opção estratégica a fim de avançarmos na superação das contradições no processo de escolarização mais precarizado.

A lente que deverá ser utilizada para refletir sobre a organização do trabalho pedagógico da escola do campo é aquela que considera a complexidade e as contradições de um sistema educacional tecido no interior da sociedade capitalista, que é dividida em classes.

Assim, a condição sine qua non para a compreensão da organização e do funcionamento do sistema educativo, bem como do papel que a escola desempenha na contemporaneidade é preciso reconhecer que a educação não pode ser pensada de forma descolada da realidade mais ampla. A escola não é um objeto posicionado fora da sociedade de classes, pois sofre os reflexos impactantes das transformações sociais e à medida que as condições históricas vão se alterando, a escola também sofre alterações (BEZERRA NETO e BEZERRA, 2011).

Para Dermeval Saviani (2009), o papel da escola contemporânea é propiciar ao aluno o desenvolvimento da consciência crítica e das capacidades para analisar e compreender a história, a organização da cultura e os processos de trabalho; a escola deve ajudar a criança a "ler”, “pensar” e viver o mundo.

E nesta perspectiva, compreende-se que é papel da escola revelar ao aluno o que a experiência da vida cotidiana oculta, sendo que cabe à comunidade escolar possibilitar ao aluno o avanço no conhecimento, bem como fomentar a reflexão crítica em torno das mais diversas questões que se relacionam com a realidade concreta, e não somente com o cotidiano imediato do alunado (SAVIANI, 2009). 
Portanto, a ação do professor é imprescindível, não bastando a ele se preocupar em fazer bem o trabalho que faz, também é preciso que reflita sobre como faz, sobre as implicações e consequências do que faz. Entendemos que toda ação pedagógica é, necessariamente, ação política e como tal deve ser planejada. E, é a partir desta necessidade de planejamento da ação pedagógica, no sentido de almejar os objetivos determinados, que identificamos a organização do trabalho pedagógico como um elemento relevante e imprescindível que deve acontecer no âmbito da coletividade escolar (ORSO, 2008).

É a organização do trabalho pedagógico que delineia as mediações sociais na esfera escolar definindo, com ou sem coerência, como serão desenvolvidas as atividades educativas que ocorrerão desde a sala de aula até o refeitório. Certamente, a coerência entre o projeto educativo e a organização do trabalho pedagógico pode ser entendida como "divisor de águas" entre os projetos históricos que guiam os projetos de educação e, em última instância, a organização do trabalho pedagógico.

Esta organização não se dá de modo espontâneo, ela é pensada a partir de um projeto de educação mais amplo que se estabelece de modo condizente com os pressupostos de um projeto histórico de sociedade; é um plano permeado pela luta de classes que ora se volta aos interesses da classe trabalhadora, ora aos interesses do sistema capitalista.

De tal modo a organização do trabalho pedagógico concretizada na prática pedagógica corrobora, ou não, para a consolidação de um processo educativo que se coloca a favor dos interesses da classe trabalhadora.

\section{Limites e possibilidades de organização do trabalho pedagógico}

A reflexão acerca da organização do trabalho pedagógico nas escolas do campo se dará em torno de dois aspectos fundamentais, a saber:

1. Condições materiais objetivas, como as relacionadas ao material pedagógico, infraestrutura, entre outros; 
2. Condições subjetivas relacionadas à formação dos profissionais que atuam na escola e ao comprometimento com o projeto de educação.

Tais aspectos mantêm relações de simbiose entre si e são permeados pelos interesses de classes, sendo que se configuram como os principais elementos que irão delinear o alcance de um projeto educativo.

Também podemos afirmar - e por que não? - que estes aspectos são determinados, em última instância, pela correlação de força na disputa de projetos de classe. E isto resulta em definir pelo uso deste ou daquele livro didático, a contratação ou não de determinado dirigente de educação etc.

E é neste sentido que pensar as possibilidades de projetos de educação e, mais particularmente, as possibilidades na educação do campo, requer um exercício cuidadoso e responsável. Pensar a perspectiva teórica dos materiais utilizados, dos planos de ensino, do projeto de formação continuada de professores e de outros elementos relacionados à escola é fundamental para entender a concepção de organização do trabalho pedagógico, e mais amplamente o projeto educacional.

A escolha do livro didático, por exemplo, tem se tornado uma questão muito abordada nas escolas do campo, pois muitas unidades de ensino apontam de modo explícito a preocupação em manter a coerência do projeto pedagógico com os conteúdos e abordagens do livro didático adotado.

A escolha do livro via MEC acontece a cada três anos nas escolas pertencentes aos municípios que possuem convênio com o PAR (Plano de Ações Articuladas) e que, por meio do Programa Nacional do Livro Didático (PNLD), disponibiliza algumas coleções a serem solicitadas pela equipe escolar. Para o ano letivo de 2013 , foram disponibilizadas às escolas do campo que atendem a demanda do Ensino Fundamental - anos iniciais, coleções de apenas duas editoras: Editora Moderna (Projeto Buriti) e Editora FTB (Coleção Girassol).

Em nossas inserções nas Secretarias Municipais de Educação, percebemos que há uma crítica recorrente em relação ao processo de escolha do livro didático nas escolas do campo, pois as opções do PNLD Campo são reduzidas. Porém, mesmo diante das 
reduzidas opções, esta escolha consiste em momentos de reflexão, visto que deve ser pautada em critérios condizentes com os objetivos definidos nas etapas de concepção e planejamento da ação educativa.

Se o objetivo da ação educativa é formar crianças que saibam ler e escrever, decodificar o sistema alfabético, qualquer material didático serve. No entanto, se o objetivo é formar leitores e escritores aptos a compreender e pensar a realidade concreta no sentido de colaborar na construção de estratégias para a superação das contradições da sociedade capitalista, neste caso, o material didático e todos os outros recursos adquirem um significado bastante específico e deve ser pensado com critérios. Assim, talvez seja relevante buscar a compreensão do que está nas entrelinhas do material didático-pedagógico e de apoio utilizado nas escolas do campo.

Obviamente, esta é apenas uma pequena parte de um universo muito mais amplo de análise e reflexão, sendo que muito provavelmente possa ser insuficiente para tornar a organização do trabalho pedagógico coerente.

\section{O trabalho didático em escolas do campo e estratégias de ensino na perspectiva histórico-crítica}

Objetivando a melhor compreensão do trabalho pedagógico desenvolvido em unidades de ensino do campo, tomamos como ponto de partida as práticas das escolas do campo de um município do interior paulista.

Analisamos o Plano de Ensino da Escola do Campo de um município do interior do estado de São Paulo do ano de $2010^{2}$, que é resultante do planejamento coletivo dos professores das escolas do campo e este documento nos permitiu avançar na compreensão de como está se organizando o trabalho pedagógico em escolas do campo.

O documento aponta a interlocução nas diferentes áreas do conhecimento escolar, nas diferentes disciplinas, sendo que desenvolve o trabalho pedagógico a partir

\footnotetext{
${ }^{2}$ O Plano de ensino, neste trabalho, é utilizado como documento base para as análises e reflexões que tecemos em relação à organização do trabalho pedagógico nas escolas do campo.
} 
de temas geradores ou eixos temáticos ${ }^{3}$. Para Clésio Acilino Antonio e Marizete Lucini (2007), o trabalho com temas geradores na educação do campo surge em decorrência das experiências dos movimentos sociais do campo, em especial os que desenvolvem projetos de educação popular.

\begin{abstract}
A opção pela organização curricular a partir do Tema Gerador nasce e se desenvolve na reflexão experienciada pelos movimentos sociais, que compreendem a educação e a escola como parte de um projeto de desenvolvimento e o próprio movimento como sujeito educativo. No entanto, os sistemas municipais e estaduais de ensino, ao orientar a formação continuada de professores do campo, optando pela organização curricular a partir dos Temas Geradores tendem a efetivar essa proposta de forma diferenciada, porque dissociada de uma opção política de transformação social orgânica, correndo-se o risco desta opção tornar-se apenas uma forma diferenciada de organizar o currículo, não correspondendo que a educação das classes trabalhadoras seja tomada nas mãos pelos sujeitos que a compõem, os trabalhadores. (ANTONIO e LUCINI, 2007, p. 186)
\end{abstract}

Para o grupo de professores que desenvolveu a proposta no município em questão, os temas geradores facilitam o trabalho dos professores e o aprendizado dos alunos, pois esta metodologia tenta estabelecer relações com o cotidiano e com a vida no campo, de modo que oferecem subsídios para discutir a realidade para além do imediato. Tais temas são trabalhados em grupos temáticos, divididos em bimestres, e essencialmente compõem os conteúdos relativos ao ensino de história, geografia e ciências. Atualmente, estão definidos e divididos da forma descrita abaixo.

\begin{tabular}{|c|l|}
\hline $1^{\circ}$ Bimestre & Identidade e Diversidade (família, tradições culturais, etnia) \\
\hline $2^{\circ}$ Bimestre & $\begin{array}{l}\text { O trabalho no Campo (boia-fria, agricultura familiar, assentado, meeiros, } \\
\text { arrendatários, trabalhador rural, posseiros grileiros, trabalho infantil, } \\
\text { cooperativismo, mecanização agrícola...) }\end{array}$ \\
\hline $3^{\circ}$ Bimestre & $\begin{array}{l}\text { Conquista da Terra (migrações, imigrações, profissões, movimentos sociais, } \\
\text { MST, Feraesp...) }\end{array}$ \\
\hline $4^{\circ}$ Bimestre & $\begin{array}{l}\text { O homem e o meio ambiente (agronegócio, agroecologia, agricultura, } \\
\text { monocultura...) }\end{array}$ \\
\hline
\end{tabular}

\footnotetext{
${ }^{3}$ Nos documentos analisados aparecem deliberadamente as duas denominações.
} 
O compromisso e a disposição docente são elementos fundamentais para que sejam bem sucedidas as propostas mais audaciosas de escola do campo e, para tal, a participação efetiva nos momentos de planejamento da ação pedagógica é primordial.

Cabe salientar que as propostas pedagógicas que se respaldam em temas geradores não estão isentas de contemplar os conteúdos regulares das propostas curriculares de ensino, a considerar que as expectativas de aprendizagens são as mesmas tanto para o aluno das escolas do campo, quanto para o aluno da escola do perímetro urbano. E, tão relevante quanto considerar e valorizar o trabalho rural e os saberes dos alunos é garantir que os sujeitos do campo conheçam e se apropriem dos conhecimentos científicos, artísticos, filosóficos, estéticos historicamente elaborados pela humanidade. Em Gramsci (1999) encontramos a afirmativa que o ser humano deve educar-se científica e culturalmente, galgando níveis mais complexos, sem romper com sua vital ligação com a cultura popular e senso comum. "A filosofia da práxis não busca manter os simples na sua filosofia primitiva do senso comum, mas busca, ao contrário, conduzi-los a uma concepção de vida superior" (GRAMSCI, 1999, p. 103).

O trabalho com os ditos temas geradores no município analisado iniciou-se no ano de 2006, a partir das Conferências e Seminários Regionais de Educação do Campo contando com a experiência acumulada da equipe gestora que desenvolveu o Projeto das Escolas do Campo em outros municípios do Estado de São Paulo. Desde então, a cada ano os temas geradores são rediscutidos e garantidos nos planejamentos das escolas do campo de todas as séries/anos, e como indicado acima tratam de temas que se referem aos interesses da classe trabalhadora, porém não são aprofundados na fase da alfabetização (Séries Iniciais). A fonte em que buscaram os temas geradores é Paulo Freire (2011), em A importância do ato de ler que, apesar de referir-se ao processo de alfabetização de adultos, nas escolas do campo de Matão, teve sua metodologia expandida para o Ensino Fundamental regular.

Temas geradores são temas fundamentais que vem sendo debatidos, toda vez que possível, de forma introdutória, na etapa da alfabetização, e que se acham retomados e propostos de modo problematizador nos textos que compõem a pós-alfabetização. (FREIRE, 2011, p. 56) 
Trabalhar nesta perspectiva também gerou ônus. A Equipe Pedagógica da Secretaria de Educação relatou que alguns docentes encontram dificuldades em desenvolver trabalhos educativos integrados contemplando alguns temas, como também a preocupação em contextualizar as temáticas com a realidade local bastante particular e, ainda, alguns docentes que alegam existirem temas que "não se encaixam na realidade dos alunos." Com isso, percebemos alguns indícios de resistência por parte de alguns professores em desenvolver um trabalho educativo respaldado na concepção de escola do campo. Em relação a isso, Alexandre Luiz Martins de Freitas (2004) aponta

No decorrer das discussões foram identificadas algumas das causas que permearam as diferentes concepções e interesses da comunidade escolar interna, em especial, do grupo de professores: 0 descomprometimento de alguns professores com as lutas da comunidade, a visão subjacente que alguns educadores têm dos movimentos sociais - em especial o MST, que naquele momento participava do debate; o discurso progressista e a sua prática conservadora; o receio de interferências externas à escola, interpretadas como possibilidade de desestabilização do isolamento da Escola do Campo, que até então estava "a salvo" de supervisão e avaliação; a formação do professor para trabalhar com a realidade do campo e o sentimento de não pertencer ao campo. (FREITAS, 2004, p. 6)

Segundo o autor, algumas escolas inviabilizaram a implantação da proposta, de modo que os entraves ficaram explícitos. Nestes casos, a resistência é manifestada através de questionamentos sobre a existência de legislação pertinente e sobre a obrigatoriedade de se adequar à proposta de escola do campo. Entendemos que contradições como estas são frequentes e imprescindíveis, à medida que possibilitam a reflexão acerca da real necessidade de projetos e conteúdos específicos para as escolas do campo.

É interessante destacar que, apesar das influências dos estudos de Paulo Freire nos projetos de escola do campo, o desenvolvimento do trabalho pedagógico, no caso analisado, não inclui os círculos de cultura e as fichas de cultura e alfabetização, próprios do método freireano. Sobre o método de Freire e, em especial, sobre os círculos de cultura, encontramos em Beisiegel (2010) 
Como outras importantes criações, o Método Paulo freire de Alfabetização também apresentava notável simplicidade. $O$ educador entendia que mesmo as palavras geralmente empregadas para designar os vários elementos da prática educativa, tais como "escola", "classe", "professor", "aluno" etc., estavam impregnadas de significações inaceitáveis, conotavam orientações "domesticadoras" da educação brasileira tradicional. Por isso mesmo, já a nomenclatura que adotava no método de alfabetização exprimia a intenção de alterar radicalmente as práticas então usuais na educação do adulto analfabeto. As "classes" eram substituídas pelos "círculos de cultura", os "alunos" pelos "participantes dos grupos de discussões", os "professores" cediam lugar para os "coordenadores de debate". De igual modo, a "aula" era substituída pelo "debate" ou pelo "diálogo" entre educador e educandos e o "programa" por "situações existenciais" capazes de desafiar os agrupamentos e de levá-los a assumir posições de reflexão e crítica diante das condições dessa mesma existência. (BEISIEGEL, 2010, p. 42)

Nesta mesma perspectiva, as originalmente onze fichas de cultura que compõem o método freireano reproduziam imagens (em desenho, pinturas, fotografias etc.) que retratavam cenas cotidianas ou não; os conteúdos destas fichas de culturas eram variados, por exemplo, a ficha de número 2 retratava um índio com arco e flecha, a de número 5 uma mulher fazendo objetos de barro, e a de número 6 os objetos produzidos pela mulher, e assim por diante; tratava-se de modo geral, da ação humana na natureza, apesar de a ficha número 4 apresentar um gato caçando um rato. Freire (1963) relata que os trabalhos de alfabetização iniciavam-se a partir da discussão do conceito de cultura pois, segundo o autor, este procedimento possibilitaria ao adulto analfabeto reformular seu saber e transformar sua realidade.

Precisávamos, ainda, de algo com que ajudássemos o analfabeto a iniciar aquela modificação de suas atitudes básicas diante da realidade. Com que ele desse começo à reformulação de seu saber preponderantemente mágico. Precisávamos que esse algo fosse um sistema de motivação para o analfabeto querer ele mesmo montar seu sistema de sinalizações. Motivação que viesse se somar à sua apetência educativa, em relação direta com a transitivação de sua consciência. Era preciso, por outro lado, superar certo fatalismo, sobretudo dos homens menos transitivados dos campos, que responsabilizaram Deus ou o destino, ou ainda a sina, pelos erros de uma estrutura arcaica e desumana. Pareceu-nos então que o caminho seria levarmos ao analfabeto, por meio de reduções, o conceito antropológico de cultura. (FREIRE, 1963, p. 14) 
Em nossa análise, os ditos temas geradores apresentados acima, são concebidos e desenvolvidos a partir de uma perspectiva distante da freireana ${ }^{4}$, pois na concepção de Paulo Freire (2011) os temas geradores decorrem do levantamento do universo vocabular junto aos educandos, e posteriormente há a seleção das palavras geradoras, e estas deveriam atender ao duplo critério da riqueza fonêmica e da pluralidade de engajamento na realidade local, regional e nacional.

(...) a melhor palavra geradora é aquela que reúne em si a maior "porcentagem" possível do critério sintático (possibilidade ou riqueza fonêmica, grau de dificuldade fonêmica complexa, de manipulabilidade dos conjuntos de sinais, as sílabas etc.), semântico (maior ou menor intensidade do vinculo entre a palavra e o ser que a designa etc.) e pragmático (maior ou menor teor de conscientização de reações socioculturais que a palavra gera na pessoa ou grupo que a utiliza.) (MACIEL, 1963, p.25)

Nas escolas do campo analisadas, os temas geradores não têm sua gênese no levantamento do universo vocabular do educando, e, sobretudo não estão relacionados ao critério sintático, portanto, se constituem na verdade como eixos temáticos que norteiam de modo significativo as atividades em sala de aula.

Em nosso entendimento, os eixos temáticos são expressões relevantes para a compreensão da realidade contemporânea, visto que remetem às grandes contradições impostas pela sociedade capitalista à classe trabalhadora. E se aproximam da proposta de complexos temáticos propostos por Pistrak (2000), pedagogo da revolução russa, que aponta a relevância de se organizar o trabalho pedagógico por meio do programa dos complexos, na medida em que este é o único sistema que garante uma compreensão da realidade atual de acordo com o método dialético. A partir desta compreensão, o sistema de complexos temáticos deixa de ser simplesmente uma boa técnica de ensino, para ser um sistema de organização do programa justificado pelos objetivos da escola (PISTRAK, 2000, p. 134).

Para Luiz Carlos de Freitas (2009), a essência do trabalho pedagógico por meio dos

\footnotetext{
${ }^{4}$ Para Freire os temas geradores são palavras que surgem a parir do diálogo entre educandos e educadores nos círculos de cultura,e estas devem ser utilizadas para alfabetizar, sendo que o critério essencial para a seleção de tais as palavras consiste em contemplar os diferentes níveis de dificuldades ortográficas.
} 
complexos temáticos está na possibilidade de articular as bases da ciência, os conceitos das disciplinas de forma dialética, através do trabalho, promovendo o seu diálogo com a prática social mais ampla. Constitui-se como uma boa alternativa pedagógica para visualização da posição integrada das disciplinas (sem disciplinarizar) num esforço conjunto para explicar e transformar "um pedaço da realidade" (FREITAS, 2009, p. 72). Neste sentido, para Pistrak (2000)

(...) o estudo dos complexos na escola apenas se justifica na medida em que eles representam uma série de elos numa única corrente, conduzindo à compreensão da realidade atual. Os temas devem encadear-se, observar uma continuidade entre si, numa ordem determinada, possibilitando uma ampliação gradual do horizonte do aluno, suscitando nas crianças uma concepção clara e nítida de nossa vida e de nossa luta, e proporcionando uma educação de tendência determinada. Só poderemos atingir os objetivos atribuídos à escola concentrando as disciplinas através deste método dialético gradual. (...) (PISTRAK, 2000, p. 137)

Compreende-se que para se trabalhar com os complexos temáticos, o corpo docente deve ter, além de uma boa formação em torno desta metodologia, clareza de objetivos e de intencionalidade da ação educativa; bem como ter um grau elevado de familiarização e conhecimentos em torno das principais discussões que se relacionam com as temáticas propostas. Isso sem apontar a evidente necessidade do comprometimento ao abordar tais temas. Para ilustrar esta afirmativa, podemos utilizar o Tema Gerador Conquista da Terra, Movimentos Sociais e MST. Do ponto de vista do debate e do envolvimento político do professor, há duas maneiras antagônicas para se abordar a temática dos movimentos sociais de luta pela terra:

1 - com conhecimento e comprometimento com a causa da luta pela terra, em que se discute com os alunos a formação latifundiária no Brasil, problematizando a ação de criminalização em torno dos movimentos sociais exercida pela mídia brasileira, abordando as chacinas sanguinolentas contra trabalhadores ocorridas nos assentamentos e em outras circunstâncias de luta, no decorrer da década de 1990. Ou,

2 - com comprometimento com o capital na sua vertente do campo, o agronegócio, 
que condena a luta pela terra e a caracteriza como "invasão"; que descaracteriza as manifestações dos trabalhadores em nome da acumulação do capital, chamando-as de "baderna”, sem questionar a desigualdade social provocada pelo modo de produção e, sem questionar o padrão de acumulação que produz uma massa de explorados no campo e nas cidades.

No entanto, é comum o corpo docente, para não assumir posturas consideradas polêmicas, visto que supostamente buscam a neutralidade, isentarem-se do debate e desenvolverem o trabalho pedagógico a partir de eixos temáticos que permitam abordagens menos problematizadoras da estrutura econômica desigual. De tal modo, há predileção em abordar temas que permitam a análise do micro, do fragmentado, do cotidiano, do indivíduo. Enfim, eixos temáticos que possam dispor de eufemismos, e que, de preferência, culpabilizem o indivíduo, e somente o indivíduo, por sua ação predatória na sociedade.

Neste sentido, com a finalidade de ilustrar o que estamos sinalizando, sublinhamos os trabalhos desenvolvidos em torno da temática do meio ambiente, na qual se valoriza o amor pela terra, o respeito à natureza e rejeita-se o uso de agrotóxicos, mas devemos nos perguntar: Há questionamentos sobre o porquê não se investe em uma rede de tratamento de água? Existem trabalhos pedagógicos que problematizem os dejetos industriais que têm ocasionado a recente matança de peixes e de outras espécies da fauna e flora aquática em rios próximos a escola? Ou ainda nos rios que compõem as Bacias Hidrográficas do estado? Há trabalhos pedagógicos que busquem estudar as políticas públicas de proteção ambiental em âmbito municipal, estadual, nacional e mundial?

As imagens abaixo expressam claramente o posicionamento que estamos requerendo; versam sobre um exemplo das diferentes abordagens a que estamos nos referindo. Trata-se de um material que foi produzido por alunos de $5^{\circ}$ ano (antiga $4^{\mathrm{a}}$ série) de escolas municipais a partir de oficinas de História em Quadrinhos (HQ). 


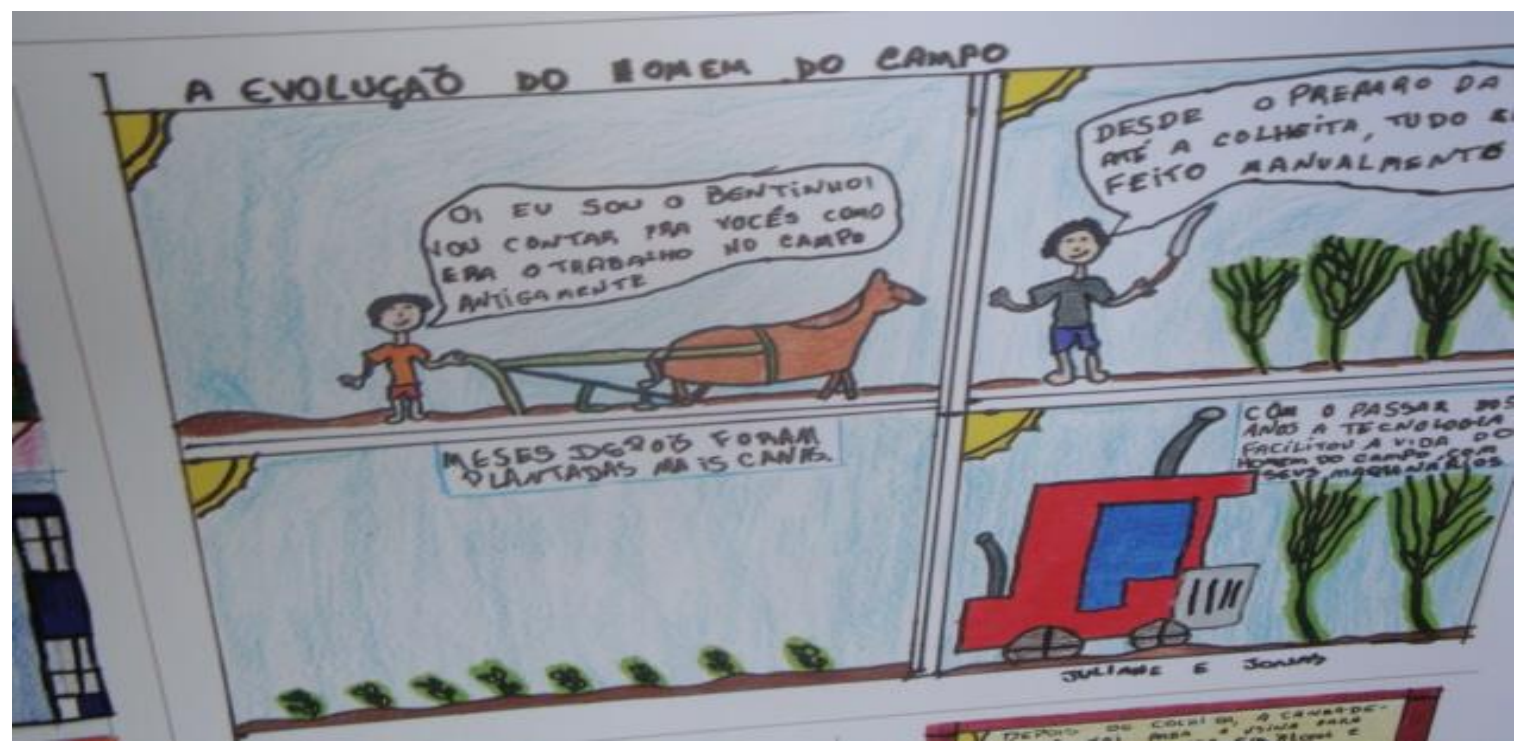

Painel gigante elaborado por alunos de escolas do campo (Acervo pessoal da pesquisadora, 18/05/2012).

A produção textual acima se intitula A evolução do homem do campo, e nos fornece alguns elementos fundamentais para o debate das diferentes abordagens possíveis para se discutir o trabalho no campo. Sobretudo, observemos qual o entendimento do alunado em relação ao desenvolvimento tecnológico no campo. E quais os possíveis encaminhamentos que deveriam ser tomados pelos docentes.

Para a discussão que nos interessa fazer, teremos de transcrever a HQ. No primeiro quadro o aluno redige: "Oi eu sou Bentinho! Vou contar para vocês como era o trabalho no campo antigamente", no segundo aparece "Desde o preparo da terra até a colheita, tudo era feito manualmente", em seguida o aluno escreve "meses depois foram plantadas mais canas", e para terminar "Com o passar dos anos a tecnologia facilitou a vida do homem do campo com seus maquinários".

Neste outro painel, aparece uma HQ elaborada por aluno da mesma escola e ano/série; esta, por sua vez, traz além dos balões de diálogos, um relato sobre o processo de elaboração da HQ. 


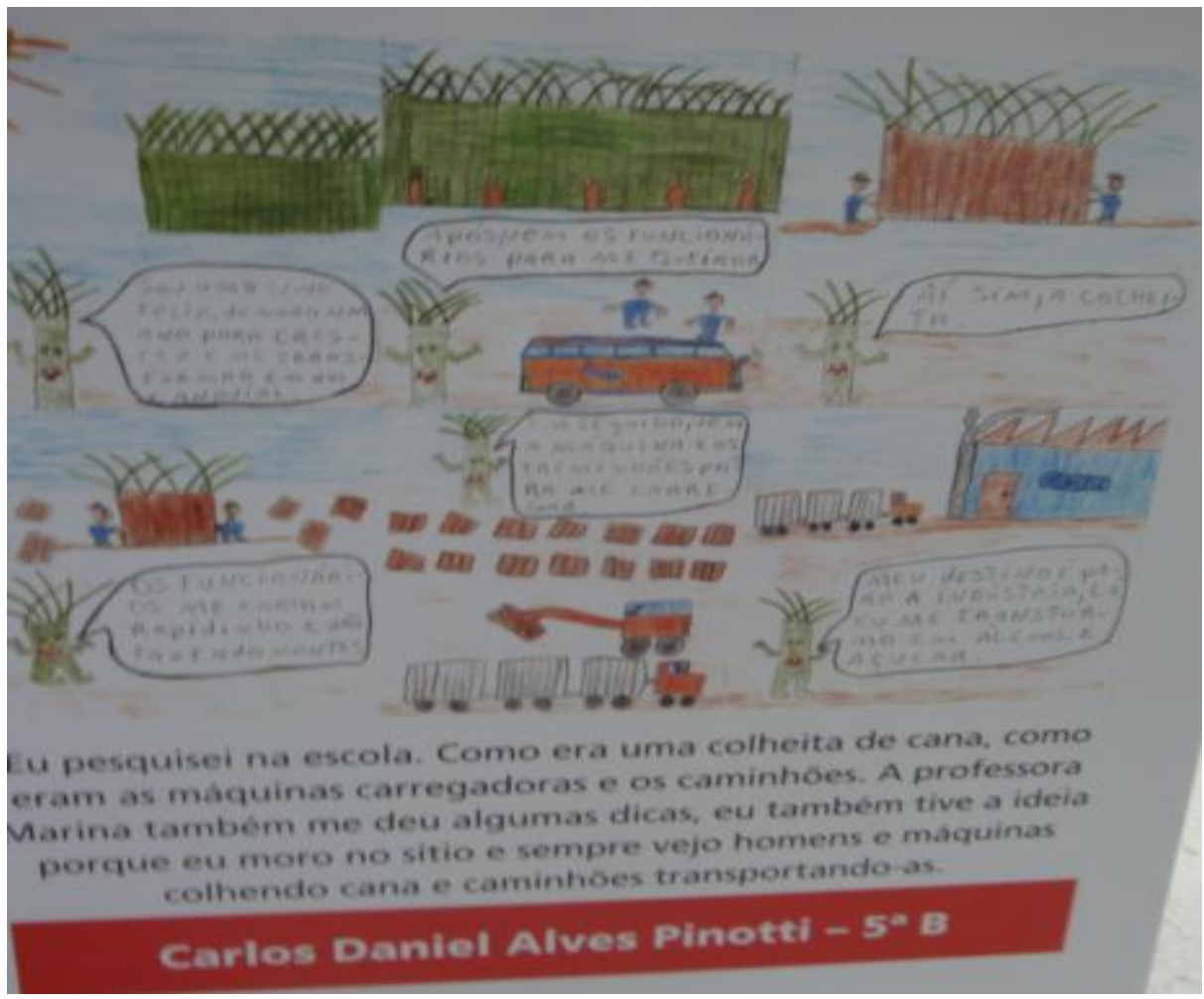

Painel gigante com HQ produzida por alunos da escola do Campo Helena Borsetti (arquivo pessoal da pesquisadora, 18/05/2011).

Trata-se de um monólogo, em que um pé de cana relata quais são as etapas de um processo produtivo. Abaixo, transcrevemos os balões, respectivamente:

Balão 1: Sou uma cana feliz demoro de um ano para outro para crescer, e transformar em um canavial.

Balão 2: Após, vem os funcionários para me queimar.

Balão 3: Ai sim, a colheita.

Balão 4: Em seguida vem as máquinas e os treminhões para me carregar.

Balão 5: Os funcionários me cortam rapidinho e vão fazendo montes.

Balão 6: meu destino é a indústria lá me transformo em álcool e açúcar.

Tendo como subsídio de análise as produções dos alunos, percebemos que na concepção retratada por eles a tecnologia é um elemento positivo para o trabalho no campo e melhora a qualidade de vida do trabalhador, e que "antigamente" o trabalhador rural vivia descalço e de ferramenta na mão, desenvolvendo um trabalho braçal. Certamente, este é um espectro possível da tecnologização dos meios de produção, no entanto, é imprescindível que o adulto na figura do professor problematize as 
consequências negativas do avanço do capital no campo, pois mesmo tendo se tornado comum o uso de máquinas na produção agrícola, o tempo de trabalho do camponês não foi reduzido. Haja vista que, como aponta Suchodolski (1976), a máquina está destinada a aumentar a produtividade e a reduzir o tempo de trabalho. Todavia, nas mãos do capitalista ela se converte em um poderoso meio para aumentar o tempo de trabalho (SUCHODOLSKI, 1976, p. 69). Neste sentido, em um processo produtivo mecanizado, o trabalho humano se converte em mero apêndice da máquina que impõe o modelo, a velocidade e o tempo de produção.

Com este exemplo, acreditamos evidenciar que as diferentes maneiras de conduzir o desenvolvimento do trabalho pedagógico remetem aos aspectos da luta de classes, que tem acarretado práticas pedagógicas contraditórias.

E é neste sentido que um olhar diferenciado para a formação dos educadores se faz necessário, devido à complexidade da intenção político-pedagógica desta proposta de formação humana; deste modo, para atingir a qualidade de ensino que se almeja devem ser trabalhadas duas dimensões indissociáveis da prática docente, quais sejam: a formação técnica, que pressupõe o domínio dos conteúdos curriculares e amplos conhecimentos científicos e culturais socialmente produzidos e historicamente acumulados e a formação política, entendida como o trato que é dado ao conhecimento e, análise da totalidade. Cabe destacar que tais dimensões da formação e do trabalho docente não estão subordinadas entre si, cada uma destas têm perspectivas próprias.

Mesmo considerando que a formação técnica e formação política são dimensões independentes entre si, entendemos que o comprometimento e a coerência política por parte de toda a equipe escolar com a educação, são elementos fortes que podem definir ou redefinir todos os princípios educativos outrora elaborados, sobretudo, de modo a comprometer o desenvolvimento de todo o trabalho coletivo e o planejamento de ações que, em última instância, expressam o empenho na formação dos futuros organizadores da sociedade.

Também, isto não implica que a dimensão política na formação docente prevaleça em detrimento da dimensão técnica, muito pelo contrário. Saviani (2009, p. 76) afirma que a dimensão política da educação envolve a apropriação dos instrumentos culturais, ou seja, o conhecimento. Para o autor 
(...) conclui-se que a importância política da educação reside na sua função de socialização do conhecimento. É realizando-se na especificidade que lhe é própria que a educação cumpre sua função política. Daí ter eu afirmado que, ao dissolver-se a especificidade da contribuição pedagógica, se anula, em consequência, a sua importância política. (SAVIANI, 2009, p. 79)

Isto nas escolas das áreas rurais traduz-se em trabalhar na perspectiva de garantir aos estudantes do campo a apropriação do conhecimento científico, cultural e tecnológico elaborado pela humanidade, garantindo também, o desenvolvimento da historicidade que busca traçar o percurso destes conhecimentos desde sua origem até os dias atuais.

Destacamos a seguir uma estratégia de ensino recorrente em escolas do campo e que a nosso ver pode - ou não - favorecer a apropriação dos conhecimentos necessários ao estudante do campo na perspectiva em que estamos tratando. Segue na íntegra quadro retirado de um documento referente às escolas do campo pesquisadas, que traz algumas das datas comemorativas previstas no calendário escolar e que são trabalhadas em todos os anos/séries da Educação Básica.

\begin{tabular}{|l|}
\hline $\mathbf{2 1}$ de Março: Dia Mundial pela Eliminação da Discriminação Racial \\
\hline $\mathbf{1 4}$ de abril: Dia da Conservação do Solo \\
\hline $\mathbf{1}$ de maio: Dia do Trabalhador \\
\hline $\mathbf{1 7}$ de junho: Dia do Migrante \\
\hline $\mathbf{1}$ de julho: Dia Mundial do Cooperativismo \\
\hline $\mathbf{1 5}$ de agosto: Primeira Greve Geral Brasileira - Rio de Janeiro - 1903 \\
\hline $\mathbf{2 2}$ de setembro: Morre Antonio Conselheiro, em Canudos, Bahia, 1897 \\
\hline $\mathbf{1 5}$ de outubro: Dia do Professor \\
\hline $\mathbf{2 0}$ de novembro: Morte de Zumbi dos Palmares - 1695 \\
\hline $\mathbf{1 0}$ de dezembro: Dia Mundial dos Direitos Humanos \\
\hline
\end{tabular}

Estas datas são incorporadas às atividades das escolas do campo que, no caso analisado, servem como interlocutoras entre os conteúdos a serem ensinados e a realidade concreta. A concepção que subsidia esta ação educativa é que a história é 
construída pelas lutas sociais e tais lutas devem ser valorizadas, em especial a luta dos sujeitos que participam da conquista da terra. Trabalhar com datas importantes de conquistas sociais, inclusive a comemoração das datas de criação dos assentamentos de esferas nacionais e regionais, remete à necessidade de engajamento coletivo na conquista de direitos sociais.

Neste sentido, ressaltamos que a diversidade de datas que remetem à multiplicidade de conquistas sociais da classe trabalhadora no contexto da sociedade capitalista pode possibilitar maior sensibilização, identificação e maior adequação ao se trabalhar com o calendário. Por exemplo, explorar o porquê do dia 8 de março ser considerado o dia da Mulher, quais as origens desta data e a que se refere.

Certamente, estas datas, se trabalhadas de modo contextualizado, com o cuidado de desmistificar alguns dos significados a elas atribuídos, podem possibilitar ampla reflexão crítica por parte dos alunos em relação à história do povo brasileiro, em relação à própria história e em relação "ao papel” que desempenham ou podem desempenhar na sociedade. Advertimos, porém, dos riscos ao incorporar tais datas apenas como festividades, pois estas podem se tornar apenas mais um feriado, ponto facultativo ou coisa afim.

Aos educadores que atuam na escola cabe direcionar o olhar para perceber de que modo as datas comemorativas são trabalhadas, e de que modo professores e alunos se apropriam de datas como, por exemplo, dia da luta campesina e da Marcha Nacional pela Reforma Agrária (MST) ou 01 de junho, dia nacional do cooperativismo.

\section{Considerações finais}

A organização do trabalho pedagógico da escola do campo pode apontar alguns caminhos para avançarmos em relação à discussão de um projeto de educação que beneficie, de fato, a classe trabalhadora. No entanto, reconhecemos que ainda há muitos limites na formulação de propostas pedagógicas para o campo, haja vista que muitos projetos de ensino se respaldam em concepções pedagógicas burguesas, que camuflam seus verdadeiros objetivos, quais sejam: esvaziamento dos conteúdos. 
Essas concepções pedagógicas burguesas a partir de discursos falsamente democráticos sobre a diversidade, inclusão, e respeito às diferenças acabam por naturalizar as desigualdades socialmente forjadas, tratando-se de verdadeiras estratégias de dominação sobre a classe trabalhadora, pois ao evocar narrativas que remetem a tempos individuais de aprendizagem, cotidiano do aluno etc. destitui-se o conhecimento.

Para Saviani (2009, p. 50), sem conteúdos relevantes, conteúdos significativos, a aprendizagem deixa de existir. Parece-nos, pois, fundamental que se entenda isso e que no interior da escola, atuemos segundo essa máxima: a prioridade de conteúdos, que é a única forma de lutar contra a farsa do ensino. Por que esses conteúdos são prioritários? Justamente porque o domínio da cultura constitui instrumento indispensável para a participação política das massas.

Nesta perspectiva, apontamos limites e possibilidades relacionados à dimensão política e técnica da formação/atuação docente na organização do trabalho pedagógico. A formação técnica e a formação política são dimensões que devem estar articuladas em prol de um projeto educativo que priorize a apropriação do conhecimento por parte de todos os alunos, sendo que nas escolas do campo ambas as dimensões são ainda mais valorosas devido ao longo processo de precarização, aqui já assinalados.

Outro aspecto que analisamos refere-se aos recorrentes equívocos na organização pedagógica das escolas do campo que buscam aproximar seus planos de ensino a termos utilizados por Paulo Freire, sobretudo o termo/conceito temas geradores. Cabe ressaltar que os temas geradores são portadores de especificidades culturais - pois, carregam muitos significados relacionados ao cotidiano dos educandos - e, também, de complexidade sintática. Identificamos que os usuais temas geradores, amplamente difundidos na organização do trabalho pedagógico nas escolas do campo, referem-se, na verdade, a complexos temáticos, que podem subsidiar um trabalho educativo interessante e coerente com os interesses das classes populares quando tratados de modo dialético e crítico.

Em suma, o que buscamos destacar é a necessidade de possibilitar que os filhos dos trabalhadores do campo, e da cidade, tenham acesso ao conhecimento, aos bens culturais produzidos pelo conjunto dos homens, pois historicamente isto tem sido negado à classe trabalhadora. 


\section{Referências}

ANTONIO, Clésio Acilino; LUCINI, Marizete. Ensinar e aprender na educação do campo: processos históricos e pedagógicos em relação. Cadernos Cedes, Campinas, vol. 27, n. 72, p. 177-195, maio/ago. 2007. Disponível em: < http://www.cedes.unicamp.br>. Acesso em: $14 / 06 / 2012$.

BEZERRA NETO, Luiz; BEZERRA, Maria Cristina dos Santos. Educação para o campo em discussão: reflexões sobre o Programa Escola Ativa. In: BEZERRA NETO; BEZERRA (Org.). Educação para o campo em discussão: reflexões sobre o Programa Escola Ativa. $1^{a}$ edição. São Carlos: Editora, 2011. p. 01-189.

BEISIEGEL, Celso Rui. Paulo Freire. Coleção Educadores., Recife: Fundação Joaquim Nabuco: Editora Massangana, 2010.

FREIRE, Paulo. Conscientização e alfabetização: uma nova visão do processo. Estudos Universitários: Revista de Cultura da Universidade do Recife, n. 4, p.5-22, abr.-jun.,1963.

FREIRE, Paulo. A importância do ato de ler: em três artigos que se completam. São Paulo: Coleção questões da nossa época; volume 22. Editora Cortez, 51ª edição, 2011.

FREITAS, Alexandre Martins de. Escola do campo: a proposta de Araraquara. Taquaritinga: Revista do Instituto Taquaritinguense, 2004.

FREITAS, Luis Carlos. Políticas de avaliação no estado de São Paulo, O controle do professor como ocultação do descaso. Revista Educação e Cidadania. Campinas: Editora Átomo, v. 8, n.1, p. 59-66, 2009.

GRAMSCI, Antonio. Cadernos do Cárcere. Rio de Janeiro: Editora Civilização Brasileira, volume I, 1999.

MACIEL, João. A fundamentação teórica do sistema Paulo Freire: Estudos Universitários. Revista de Cultura da Universidade de Recife, n.4, p. 25-57, abr.-jun., 1963.

MARX, Karl. Manuscritos económico-filosóficos. Lisboa: Editora Edições 70, (Tradução Artur Morão), 1964.

ORSO, Paulino José; GONÇALVES, Sebastião Rodrigues; MATTOS, Valci Maria. Educação e luta de classes. $1^{\text {a }}$ edição. São Paulo: Editora Expressão Popular, 2008.

PISTRAK, Mikhail. Fundamentos da escola do trabalho. São Paulo: Editora Expressão Popular (Tradução de Daniel Aarão Reis Filho), 2000.

SAVIANI, Dermeval. Escola e democracia. Campinas: Editora Autores Associados, 2009. Coleção Polêmicas do Nosso Tempo. 
SUCHODOLSKI, Bogdan. Teoria marxista da educação. Texto original de 1976; Tradução e organização Irena Wojnar, Jason Ferreira Mafra. Recife: Editora Massangana, Recife: 2010. Fundação Joaquim Nabuco.

Recebido em: 22/04/2014 Aprovado em: 25/02/2015

Universidade do Estado de Santa Catarina - UDESC Programa de Pós-Graduação em Educação - PPGE Revista Linhas Volume 17 - Número 33 - Ano 2016 revistalinhas@gmail.com 